\title{
ECONOMIC PLANNING AND THE KNOWLEDGE PROBLEM
}

\author{
Israel M. Kirzner
}

\section{Introduction}

It is now about 40 years since Professor Hayek decisively identified the key misconception underlying mainstream welfare economics. This misconception, Hayek argued, was responsible for failure to appreciate the critique of the possibility of rational economic calculation under central planning-a critique stated most forcefully and clearly by Mises, and further developed by Hayek himself. As has been demonstrated by Professor Lavoie (1985), the true import and significance of the Hayekian lesson was simply not grasped by subsequent welfare economists writing on the socialist calculation debate, even though Hayek's work was widely cited.

In this paper we attempt both to restate and to extend Hayek's insight concerning the "knowledge problem" and its implications for central economic planning, whether comprehensive in scope or otherwise. In the following paragraphs we cite Hayek's own formulation of his insight, and make certain observations concerning it. In subsequent sections of the paper we start from a rather different point of departure, and in this way eventually arrive at our restatement and extension of the Hayekian position-spelling out some rather radical implications of our restatement.

According to Hayek (1945, pp. 77-78):

The peculiar character of the problem of a rational economic order is determined precisely by the fact that the knowledge of the circumstances of which we must make use never exists in concentrated or integrated form but solely as the dispersed bits of incomplete and frequently contradictory knowledge which all the separate individuals possess. The economic problem of society is thus not merely a problem of how to allocate "given" resources-if "given" is taken

Cato Joumal, Vol. 4, No. 2(Fall 1984). Copyright 0 Cato Institute. All rights reserved. The author is Professor of Economics at New York University. 


\section{Cato Journal}

to mean given to a single mind which deliberately solves the problem set by these "data." It is rather a problem of how to secure the best use of resources known to any of the members of society, for ends whose relative importance only these individuals know. Or, to put it briefly, it is a problem of the utilization of knowledge which is not given to anyone in its totality.

Let us call this knowledge problem “Hayek's knowledge problem." We note, at this initial stage in our discussion, that the position might be taken that Hayek's knowledge problem does not, at least at first glance, render immediately irrelevant the paramountcy of the social efficiency norm. It is true, as Hayek pointed out, that the dispersed character of knowledge means that the economic problem is not that of allocating "given" resources, where "given resources" means resources given and known to a single mind. But surely knowledge itself is a scarce resource. So that the task of the central planner may be seen, in the light of Hayek's knowledge problem, as that of making the most effective use of the available dispersed knowledge existing in society at a given moment-with the attainment of such use constrained by the communication and search costs made necessary by the dispersed character of the available information.

It might seem, therefore, that there is nothing in Hayek's knowledge problem which places it outside the scope of economic planning. The knowledge problem, it might be argued, complicates the planning task: It introduces a newly recognized, subtle, and complex resource (knowledge); it compels attention to the special characteristics of this resource (its dispersed character); and it calls for attention to a special class of costs (those required for search and communication). But Hayek's knowledge problem can still, it might seem, be subsumed under the overall economic problem, traditionally conceived in resource-allocation terms. The central theme of this paper is to deny this understanding of the implications of Hayek's knowledge problem.'

Hayok (1979, p. 190) has more rocently deepened our understanding of the problem of dispersed knowledge as going far beyond that of "utilizing information about particular concrete facts which individuals already possess." He now omphastzes the problom of using the abilities that individuals possess to discover relevant concrete information. This leads Hayek to point out that because a person "will discover what he knows or can find out only when faced with a problem where this will help," he may never be able to "pass on all the knowledge he commands. ..." In recent unpublished work Professor Lavoie, building on insights contained in the work of Michael Polanyi, also has emphasized the relevance of "tacit knowledge" for tho social problem of utilizing dispersed knowledge. The present paper arrives at simflar conclusions but from a somewhat difforent starting point. 
In this paper I shall argue that this problem of securing the best use of dispersed knowledge, in fact, cannot be translated into a special case of the more general problem of securing an efficient allocation of society's resources. It will follow that societal planning, by its very character, is incapable of addressing Hayek's problemsuch planning can only frustrate and hamper those spontaneous market forces that are capable of engaging this knowledge problem. In order to develop these arguments it will be useful to introduce a "knowledge problem" that at first glance seems very different from Hayek's.

\section{The Individual Plan and the Knowledge Problem}

In the course of everyday life man continually plans. Economists have come to formulate the individual plan as the seeking of a maximum: The planner is intent on arriving at a constrained optimum position. This is the concept of the economizing decision articulated with special precision and force by Lionel Robbins in 1932, and widely adopted since then as the basic building block of microeconomic theory. We wish to point out that there is an inescapable potential "knowledge problem" surrounding this concept of the individual plan.

The notion of the plan presupposes some deliberately aimed-at entity-say, utility, or profit-that is to be knowingly maximized. It further presupposes known resource constraints. In Robbins' terminology, both the ends and the means are presumed to be given. It is the presumed knowledge of these planning circumstances by the planner that permits the economist to perceive the plan as the solving of a constrained maximization problem. The validity of the plan itself, it should be noted, depends entirely on the validity of the assumption that the planner in fact accurately knows the circumstances surrounding his prospective decisions. If the planner does not know what it is that he is seeking to achieve, or does not know what resources are at his command, or what the efficacy of these resources is with respect to sought-after goals, then his plan-no matter how carefully formulated-is unlikely to result in the best possible outcome.

We can now identify the knowledge problem potentially relevant to each individual plan: Because of inadequacies in the planner's knowledge of his true circumstances, his plan may fall to yield an attainable optimum. Let us call this knowledge problem the "basic knowledge problem." This will distinguish it from what we have called "Hayek's knowledge problem." It will also indicate our intention to demonstrate that Hayek's knowledge problem can be considered a special case of what we call the "basic knowledge problem." 


\section{Cato Journal}

To be sure, what we have called the "basic knowledge problem" seems, at first glance, to bear little resemblance to Hayek's. Hayek's knowledge problem consists in the dispersed character of available information; our basic knowledge problem consists in an individual's simple ignorance of the circumstances relevant to his situation. Further reflection on both Hayek's knowledge problem and our basic knowledge problem, however, will reveal the important sense in which Hayek's problem is indeed a basic one. Let us first clarify a possible misunderstanding concerning the basic knowledge problem.

\section{The Basic Knowledge Problem and the Economics of Search}

It might be argued that the basic knowledge problem surrounding every individual plan can be entirely escaped through the addition of new planning stages. After all, if a plan seems likely to fail because of inadequate availability of a necessary resource, this threatened failure need not be final; it may possibly be avoided by appropriate preliminary planning to obtain this resource. Instead of simply formulating a single plan directed at the immediate attainment of the final objective, it is necessary to introduce intermediate objectives to be pursued in the course of additional preliminary plans. Perhaps, then, the basic knowledge problem, too, merely calls for judicious preliminary planning.

From this perspective the basic knowledge problem would appear merely to represent an inadequacy in the available supply of an important resource, namely, knowledge. This inadequacy would then be seen to call for a planned search to acquire the necessary information. In principle, it might then be thought that the basic knowledge problem can be escaped; at least to the same extent that any other problem arising out of a resource shortage can be escaped. To the extent that it is worthwhile, a preliminary plan of search to overcome the shortage of necessary information may totally eliminate the basic knowledge problem. To the extent that such a costly search is held not to be worthwhile, the basic knowledge problem would seem merely to express the inescapable scarcity constraints inherent in the planner's situation. For the economist such an inescapable scarcity problem means that there is no problem at all, in the relevant sense.

To the extent that the knowledge problem is escapable, it can (and presumably will) be escaped; to the extent that it is not worthwhile escaping, there would appear to be no basic knowledge problem at all-since we defined the basic knowledge problem in terms of failure to realize an attainuble optimum. If lack of knowledge renders 
a hypothetical optimum unattainable, it can generate no basic knowledge problem. And, if the cost of acquiring the knowledge is prohibitive, then the "hypothetical optimum," while indeed "attainable," is in fact no optimum at all.

But this line of argument cannot be sustained. The basic knowledge problem potentially surrounding each individual plan is by its nature inescapable. Certainly a deficiency in knowledge may be able to be rectified by search, and the individual planner will no doubt consider, in his preliminary planning, whether such search should be undertaken or not. But the basic knowledge problem-involving possible failure to achieve an attainable optimum-remains. In fact the possibility of preliminary planning to acquire knowledge only expands the scope of the basic knowledge problem.

Let us consider an individual engaging in a plan seeking to achieve a valued objective. Let us call this "Plan A." In formulating the specific steps that should be taken in pursuing Plan $A$, the individual realizes that he lacks needed pieces of information. He thereupon engages in a plan to attain these preliminary objectives, namely, these missing pieces of information. Let us call this search plan, "Plan B." We may see Plan A as having been expanded (as a result of realized ignorance) to include the planned attainment of needed preliminary objectives, so that Plan B is "nested" within expanded Plan A. And we may identify the later steps to be taken in the course of expanded Plan A-those steps subsequent to the attainment of the information obtained in Plan B-as "Plan A'." (Plan A' consists in the steps that would have made up the originally envisaged Plan $A$ had the planner in fact not lacked the needed information.) We can easily see that the basic knowledge problem is a potential hazard both for Plan B and Plan A'. Plan A, which includes Plan B and Plan $A^{\prime}$, is of course subject to the vulnerabilities of both of them.

Even if Plan B is completely successful in attaining precisely the optimal amount of information capable of being searched for (and believed to be worth the costs of such search), Plan $A$ is nonetheless still subject to the hazards of the basic knowledge problem. After all, although our decision maker, in originally seeking to formulate Plan $A$, realized he lacked specific items of information (and therefore undertook preliminary Plan B), he may have in fact lacked far more information than he realized. (Most important, such unrealized information may have taken the form of a firm, but totally mistaken, belief in the validity of information that is totally false.) Moreover he may be mistaken in his belief that the items of information he realizes he lacks are necessary for the implementation of Plan A. He also may be mistaken in his belief that he really lacks these items of 
information (in the relevant sense of lacking). The truth may be that these items are already within his grasp.

For example, he may believe that Plan $A$, in the course of which be must communicate with individual $\mathrm{Z}$, requires information concerning Z's telephone number, information that he believes himself to lack, so that he undertakes Plan B to search for Z's telephone number. But the truth may be quite different. The truth may be that $Z$ is in fact the wrong person to speak to altogether, or again the truth may be that $Z$ is now in the very same room with our planner, so that no knowledge of Z's telephone number is in fact needed for Plan $A$. Or, it may be, our planner does not really "lack" Z's telephone number at all; he may in fact have that telephone number clearly written and identified in the list of telephone numbers that lies next to the telephone that he uses. Given these possibilities for sheer error that surround Plan $A^{\prime}$ and/or Plan B, possibilities in which the planner is entirely unaware of the extent of his ignorance, Plan $A$ (because it includes Plan $A^{\prime}$ and Plan B) may be far from optimal even if Plan B is wholly successful in terms of its own objectives. In addition it may be the case that Plan B overlooks more efficient available ways of achieving its own objectives (for example, there may be less costly methods of search of which the searcher is unaware.)

To sum up, the possibility of planned search for information perceived to be lacking does not eliminate the knowledge problem. First, the planned search may itself be undertaken without awareness that more efficient search techniques are easily available. Second, the information sought may in fact not justify the costs of search because the truth (of which the planner is unaware) is that the information is not of significance for the attainment of the planner's ultimate objectives. Third, quite apart from the information that the planner realizes he lacks and for which he may attempt to search, he may lack other information that he does not realize he lacks and for which he does not think of undertaking any planned search.

\section{Central Planning and the Knowledge Problem}

We are now in a position to appreciate Hayek's insight into the problem of dispersed knowledge as revealing the central planning task to be one that is doeply and inextricably bound up in the basic knowledge problem. Let us put ourselves in the position of the central planners, earnestly and single-mindedly seeking after the most efficient possible pattern of resource allocation.

Our task as central planners is to formulate a plan for society in a manner analogous to that in which an individual plans his own course 
of action. We formulate our social plan with respect to specific social objectives and in the light of specific perceived arrays of available social resources. ${ }^{2}$ This framework for the central plan is relevant (in principle and with the necessary changes having been made) both for comprehensive social planning and for central planning designed merely to supplement or modify, rather than totally replace, decentralized economic activity. The analogy between the social plan and the individual plan compels us, of course, to acknowledge the relevance of the basic knowledge problem for the social plan, in exactly the same way as we have seen it to be an inevitable and inescapable hazard for the individual plan. Havek's contribution permits us to recognize that the central plan may be subject to hazards (arising out of the basic knowledge problem) that might have been escaped by decentralized planning.

That the centralized plan is inescapably subject to the hazards of the basic knowledge problem follows almost trivially from the very notion of the basic knowledge problem. Because the individual planner may not be aware of his true circumstances and may be totally unaware of his ignorance, his best formulated plans may fail to yield an attainable optimum. The central planners, too, may be unaware of their own ignorance concerning the true circumstances relevant to the social plan. Our understanding of the implications of dispersed knowledge deepens our appreciation of the seriousness of the basic knowledge problem, and reveals how the hazards of this problem might have been entirely escaped in the absence of the centralized plan.

Recognition of the fact of dispersed knowledge-especially as regards "the knowledge of particular circumstances of time and place" (Hayek, 1945, p. 80)-immediately illuminates our understanding of the basic knowledge problem that threatens central planners. For a planning individual, the basic knowledge problem derives from the possibility that what he thinks he knows about his circumstances may differ from what he might have known (without additional resource expenditure) had he been more alert or aware of the true environment.

The same possibility, of course, is fully relevant for a central planner, but it is heightened by the central planner's peculiar predicament. What the central planner thinks he knows about the relevant circumstances must necessarily take the form of what he thinks he knows about the availability of dispersed bits of knowledge that can

We avoid here raising any of tho woll-known difficulties that surround (a) tho notion of a hierarchy of social goals analogous to a ranking of individual objectives, and (b) the related notions of social officiency and social choice. 
somehow, at some cost, be mobllized in formulating and implementing the social plan. There is little chance that the central planner can ever know where to find, or how to search for, all the items of dispersed information known somewhere in the economic system. Moreover there seems little chance that the central planner can ever be fully aware of the nature of extent of the specific gaps in his own knowledge in this regard. He may realize, in a general way, that there is information the location of which he is ignorant, but this gives him no clue on where to look. The end result is that the planner is unlikely to be able to exploit all the information that is within his command. Clearly the dispersal of information is responsible for a new dimension of application for the basic knowledge program.

Earlier we raised the possibility that Hayek's knowledge problem-despite its novelty-might be subsumed under the general economic problem, traditionally conceived in terms of achieving an efficient allocation of given resources (with available information included as an important given resource). We can now see how inappropriate it is for us to consider central planners as being able to grapple with Hayek's knowledge problem in terms of conventional planning to achieve a constrained optimum pattern of resource allocation. The unknown ignorance that is the heart of the knowledge problem created by the dispersal of information defies its being able to be squeezed into the Procrustean bed of the allocation plan. Just as the individual planner is unable to grapple deliberately with the basic knowledge problem surrounding all decision making, $s 0$ too is the central planner unable to invoke planning techniques to grapple deliberately with Hayek's knowledge problem.

What renders the Hayekian knowledge-problem critique of central planning so devastating is the circumstance that in a market system, with decentralized decision making, the insoluble knowledge problem confronted by central planners tends to dissolve through the entrepreneurial-competitive discovery procedure.

\section{The Entrepreneurial-Competitive Discovery Procedure}

The Hayekian case for decentralized decision making has frequently been misunderstood. All too frequently this case is presented as arguing only that the decentralized market economy escapes the problem of dispersed knowledge because prices accurately and economically convey necessary information to relevant decision makers (replacing any need for them to know all the detailed information that is dispersed throughout the system). It must be emphasized that 
while this line of reasoning is certainly present in Hayek's work, it fails to do justice to the full implications of that work.

To argue that market prices convey information, and thus directly overcome the problem of dispersed knowledge, is to make a case for markets that depends upon a dubious assumption; namely, that markets are always at or close to equilibrium. It is only in equilibrium that it can be claimed that a market participant guided by market prices is automatically steered toward those actions that will coordinate smoothly with the actions of all the other (similarly guided) market participants. Moreover, to make the assumption that markets are close to equilibrium is essentially (quite apart from our other reasons for feeling uncomfortable concerning the realism of this assumption) to beg (rather than to overcome) the Hayekian problem of dispersed knowledge. After all, just as the phenomenon of dispersed knowledge offers a formidable challenge to central planners, this phenomenon offers markets a wholly analogous challenge, namely, that of achieving, in fact, those arrays of market prices that will clear markets.

One does not "solve" the problem of dispersed knowledge by postulating prices that will smoothly generate dovetailing decisions. Dispersed knowledge is precisely the reason for the very realistic possibility that market prices at a given date are unable to clear markets and to ensure the absence of wasted resources. The truth is that the market does possess weapons to combat (if not wholly to conquer) the problem of dispersed knowledge. These weapons are embodied in the workings of the price system, but not in the workings of a hypothetical system of equilibrium prices. The importance of prices for coping with the Hayekian knowledge problem does not lie in the accuracy of the information which equilibrium prices convey concerning the actions of others who are similarly informed. Rather, its importance lies in the ability of disequilibrium prices to offer pure profit opportunities that can attract the notice of alert, profit-seeking entrepreneurs. Where market participants have failed to coordinate their activities because of dispersed knowledge, this expresses itself in an array of prices that suggests to alert entrepreneurs where they may win pure profits.

We know very little about the precise way in which pure profit opportunities attract entrepreneurial attention. But there can be little doubt about the powerful magnetism which such opportunities exert. To say that pure profit opportunities attract attention is not at all to say that awareness of these opportunities is secured by deliberate, costly search on the part of entrepreneurs. Rather it is to recognize that the lure of pure profit is what permits an individual decision 


\section{Cato Joural}

maker to transcend the limits of a given, perceived planning framework, and to escape, to some extent, the basic knowledge problem that surrounds all individual decision making. Man's entrepreneurial alertness operates at all times to place his narrow planning activities within the broader framework of human action. ${ }^{3}$ At the very same time as man is routinely calculating the optimal allocation of given resources with respect to given competing ends, he keeps an entrepreneurial ear cocked for anything that might suggest that the available resources are different from what had been assumed, or that perhaps a different array of goals might be worth striving for.

This entrepreneurial element in human action is what responds to the signals for pure profit that are generated by the errors that arise out of the dispersed knowledge available in society. It is this yeast that ferments the competitive-entrepreneurial discovery process, tending to reveal to market participants more and more of the relevant information scattered throughout the market. It is this entrepreneurial-competitive process that thus grapples with that basic knowledge problem we found inescapably to confront central planning authorities. To the extent that central planning dispaces the entrepreneurial discovery process, whether on the society-wide scale of comprehensive planning or on the more modest scale of state piecemeal intervention in an otherwise free market, the planners are at the same time both smothering the market's ability to transcend the basic knowledge problem and subjecting themselves helplessly to that very problem. The problem's source is Hayek's dispersed knowledge: Central planning has no tools with which to engage the problem of dispersed knowledge, and its very centralization means that the market's discovery process has been impeded, if not brought to a full halt.

\section{Markets, Firms, and Central Planning}

At least as far back as Coase's 1937 paper on the theory of the firm, it has been recognized that each firm in a market economy is an island of local "central planning" in a sea of spontaneously seething competitive market forces. Within the firm, activities are coordinated by central direction, not by market competition via a price mechanism. Our discussion in this paper throws light, perhaps, on the forces governing the location of the boundaries separating the realm of freely adopted "central planning" from that of the competitive price system.

30n this compare Mires (1949, pp. 253-54). 
We have seen that the replacement of market discovery (working through entrepreneurial alertness to profit opportunities) by central planning generates a new scope of potency for the basic knowledge problem arising out of the dispersal of knowledge. In a free market, therefore, any advantages that may be derived from "central planning" (for example, the avoidance of "wasteful" duplication often apparently present in situations of market rivalry) are purchased at the price of an enhanced knowledge problem. We may expect firms spontaneously to tend to expand to the point where additional advantages of "central" planning are just about offset by the incremental knowledge difficulties that stem from dispersed information. On a small scale these latter difficulties may be insignificant enough to be worth absorbing in order to take advantage of explicitly coordinated organization. Knowledge dispersed over a small geographical or organizational area may mean a Hayekian knowledge problem that is, unlike that relevant to large, complex entities, solvable through deliberate search. Beyond some point, however, the knowledge difficulties will tend to reduce the profitability of firms that are too large. Competition between firms of different sizes and scope will tend, therefore, to reveal the optimal extent of such "central planning."

On the other hand if central planning is imposed on an otherwise free market, whether in comprehensive terms or not, such planning will almost always involve the knowledge problem, and to an extent not likely to be justified by any advantages that centralization might otherwise afford. Governmentally enforced central planning sweeps away the market's delicate and spontaneous weapons for grappling with the knowledge problem. Such centralized planning is by its very nature, and the nature of the knowledge problem, unable to offer any substitute weapons of its own.

\section{Conclusion}

We should remember that the nature of the knowledge problem is such that its extent and seriousness cannot be known in advance. Part of the tragedy of proposals for industrial policy and economic planning is that their well-meaning advocates are totally unaware of the knowledge problem-the problem arising out of unawareness of one's ignorance.

\section{References}

Coase, Ronald H. "The Nature of the Firm." Economica (NS) 4 (1937): 386405.

Hayek, Friedrich A. "The Use of Knowledge in Society." American Economic Review 35 (September 1945): 519-30. Page references are to the 


\section{Cato Jounnal}

reprinted version in Friedrich A. Hayek, Individualiom and Economic Order. London: Routledge and Kegan Paul, 1949.

Hayek, Friedrich A. Law, Legislation and Liberty, Vol. 3, The Polttical Order of a Free People. Chicago: University of Chicago Press, 1979.

Lavoie, Donald. Rtoalry and Central Planning. Cambridge: Cambridge University Press, 1085 (forthcoming).

Mises, Ludwig. Human Action. New Haven: Yale University Press, 1949.

Robbins, Lionel. An Essay on the Nature and Significance of Economic Sctence. London: Macmillan and Co., 1932. (Second Edition, 1935). 


\section{"ECONOMIC PLANNING AND THE KNOWLEDGE PROBLEM": A COMMENT Leonid Hurwicz}

My comments are directed to issues raised by Professor Kirzner's analysis' rather than the various current proposals for a national industrial policy, but $I$ hope that they may be relevant as a background for analyzing such proposals. And, since I shall be indicating my disagreement with some of the points made by Professor Kirzner, let me stress that I am in complete sympathy with his point of departure, namely, the emphasis on the dtsperston of information among economic decision-making units (called by him, "Hayek's knowledge problem") and the consequent problem of transmission of information among those units.

Much of my own research work since the 1950 s has been focused on issues in welfare economics viewed from an informational perspective. The ideas of Hayek (whose classes at the London School of Economics I attended during the academic year 1938-39) have played a major role in influencing my thinking and have been so acknowledged. But my ideas have also been influenced by Oskar Lange (University of Chicago, 1940-42), as well as by Ludwig von Mises in whose Geneva seminar I took part during 1938-48.

By now there is a considerable literature in this area. ${ }^{2} \mathrm{~A}$ careful perusal of this literature, I believe, would show that Professor Kirzner's opening statement (that "the Hayekian lesson was simply not grasped by subsequent welfare economists") ${ }^{3}$ does not apply to present-day mainstream welfare economics, whether or not it applies to earlier work in this area.

Cato Journal, Vol. 4, No.2 (Fall 1884). Copyright $\odot$ Cato Institute. All rights roserved. The author is a Rogents' Professor of Economics at the University of Minnesota. 1Kiraner (1984).

'An excellent presentation of many recent ideas is found in Reiter (1977).

TRirzner (1984, p. 407). 


\section{Cato Journal.}

Let me make clear at this point that I do not intend to argue the advantages or disadvantages of whatever may be meant by "central planning" or "industrial policy." Rather, my purpose is to instill some skepticism with respect to oversimplified arguments sometimes used in this area. I shall argue that the paper before us-despite its many valuable insights-does not provide an adequate basis for forming a judgment concerning the respective merits of "the free market," "central planning," or other forms of government intervention in the economic process. (This is the Scottish verdict: neither "guilty," nor "not guilty," but "not proven.") This is so for several reasons, including the ambiguity of the terms used, the implicit assumptions postulating a "classical economic environment" (to be defined below), problems of incentives, and value judgments transcending efficiency.

Terms such as "central planning" and "free market" have many interpretations. In analyzing the merits and weaknesses of the market process it is important to distinguish perfectly competitive markets from those that are monopolistic, oligopolistic, or otherwise imperfect. For example, in a decreasing cost industry only a few firms may survive even though there is freedom of entry. Such a market may be called "free," but it is oligopolistic rather than perfectly competitive.

The well-known theorem of welfare economics asserts the Paretooptimality (efficiency) of perfectly competitive equilibrium. But there is no theoretical basis for asserting that monopolistic or oligopolistic markets result in efficient resource allocation. Indeed, elementary analysis shows that uniform price monopoly or oligopoly is, in general, Pareto-inefficient.. ${ }^{4}$ Moreover, under conditions of increasing returns, perfectly competitive equilibrium is, in general, impossible because profit maximization with parametrically treated prices would call for either a zero or infinite level of output. Therefore, it is difficult to see how one could justify, in the presence of increasing returns, the claim of efficiency of "free markets," whether the latter term is interpreted as perfect competition or merely free entry.

Difficulties with increasing returns constitute but a special case of a more general problem. The theorem guaranteeing the optimality of perfectly competitive equilibrium assumes the absence of externalities, which also excludes public goods. ${ }^{\mathrm{s}}$

The so-callod Coase Theorem, as I understand it, merely oxploros the implications of postulating that frocly acting well-informed economic agents will arrive at a Paretooptimal allocation. But uniform price monopoly or oligopoly does not satisfy this postulate.

scoonding to the usual definition of a public good, the utilization of its services by person $A$ does not detract from the possibility of utilization by person B. Government or a private party may supply a public good. 
Furthermore, as seen above, there are circumstances (such as increasing returns) where no set of prices can balance supply and demand; hence, perfectly competitive equilibrium is impossible. Thus, to guarantee both the possibility of existence of balancing prices-technically known as the existence of perfectly competitive equilibrium-and of the optimality of perfectly competitive equilibria, the relevant theorems make a series of assumptions, excluding such phenomena as externalities, public goods, increasing returns, indivisibilities, and so on. When all these assumptions (which rule out the "troublesome" phenomena) are satisfied, we speak of a classical economy or a classical environment. The theorems guaranteing the possibility and optimality of perfectly competitive equilibria therefore presuppose $a$ classical environment.

In practice, however, one often encounters nonclassical environments. Pollution is an example of an important negative externality while information derivable from new inventions or pleasure derivable from musical compositions illustrate positive externalities or public goods. National defense is another example of a vitally important public good. Bridges and dams exemplify indivisibilities, and there are many instances of economies of scale-known as "increasing returns (to scale)." I know of no basis for claiming that, in such situations, the free-market process (however defined) would yield optimal resource allocation.

It has been shown in a number of contributions (Mount and Reiter 1974; Osana 1978; Hurwicz 1977) that in classical environments the perfectly competitive price mechanism uses a minimal size message space; that is, it uses the minimum number of variables for transmitting information between economic units. This confirms Hayek's view concerning the informational efficiency of the price mechanism. But it has been shown by examples (Hurwicz 1977; Calsamiglia 1977) that in the absence of convexity, ${ }^{6}$ it may be impossible to find any efficient decentralized mechanism using a finite-dimensional message space.

In addition to the difficulties in achieving efficiency in nonclassical environments, one must note that efficiency is only one of the possible criteria on which value judgments concerning economic systems are based. Some people may be prepared to sacrifice efficiency for the sake of egalitarian ideals; for them, the fact that the market process yields efficiency may be insufficient-even if one can assume a classical environment. Of course, this attitude need not lead to the

'Inereasing returns are a special case of the nonconvexity of a production possibility set. 


\section{Cato Journal}

discarding of the market process, but perhaps to a supplementation with such devices as taxes or subsidies. Hence a case for some role of the government may be made on value judgment grounds even if it were admitted that government intervention results in lowering the efficiency of the system.

I also see another problem in relating Professor Kirzner's arguments to the above-quoted theorems concerning the optimality of competitive equilibria. The paper before us is emphatic in avoiding reliance on markets actually being in equilibrium. But it is only the position of competitive equilibrium which, under classical assumptions, is guaranteed to be optimal. So the best one can say for disequilibrium situations is that they may tend to an equilibrium. In fact, a study by Arrow, Block, and the present writer (1959) identified certain classes of situations where such a tendency toward equilibrium (that is, stability) is present. But subsequent research (for example, Scarf 1960) has shown that this tendency is not always present even in perfectly competitive markets. In any case, it is difficult to see how, in the absence of stabilizing forces, a theoretical claim can at all be made that markets produce efficiency.

The paper's major emphasis is on what the author calls "the basic knowledge problem." To the extent that this goes beyond Hayek's dispersion of knowledge, this "basic knowledge problem" seems simply to be the fact that most decisions-whether by planners, firms, or individuals - must be made without complete and accurate information. There is no disagreement on this point. But some of the discussion seems to imply that such uncertainty makes any rational behavior logically impossible.

With that I cannot agree. There do exist well-developed theories of rational behavior under uncertainty, including the theory of search. Statistical decision theory is but one branch of this discipline. But even if one accepts the practical difficulties of optimal search behavior, one is then led to the framework of so-called bounded rationality (Simon 1972; Radner 1975).

I would, of course, agree that people often act on beliefs that are factually incorrect. At best, one can only hope for action that is rational in the light of foresight-not of hindsight. But this diffeulty arises for everyone, not just for planners. True, if the planner's information

I stress the term "theoretical" bocause neither Professor Kirznor nor I attempt to doal with the cmpirical evidence concerning the actual performance of different types of economic systems.

See Kirzner (1984, p. 410): "[O]ur basic knowledge problem consists in an individual's simple ignorance of the circumstances relevant to his situation." 
or beliefs are based on imperfect transmisston, this does constitute an additional source of error. But that, again, is the Hayek probleml

As mentioned above, the market mechanism does minimize the required message space, but its claims are based on the assumption of classical environments.

In nonclassical environments or where values other than efficiency are important, a case may be made, at least, for the inadequacy of the "free market" process, and possibly in favor of a role for government intervention. But such a role should not be identified with central planning. In fact, this role may be confined to introducing and enforcing what may be called "rules of the game." In particular, this may involve the creation of property rights through patents or copyrights. Creating such rights does amount to government intervention in the free market process but does not constitute what I would call central planning. Similarly, government's role in enforcing income transfers through taxes and subsidies constitutes intervention but not central planning. The latter term should perhaps be reserved for the type of intervention that might be called micro-targeting-of which industrial policy or price controls and rationing may be examples, and in which the government makes decisions concerning outputs, inputs, or prices of specific commodities or groups of commodities. Even then it is important to distinguish between all-encompassing central planning (attempted in the Soviet Union) on the one hand, and elements of planning grafted onto an otherwise market-type economy (as is typical of Western countries) on the other. Thus one should recognize that between a laissez-faire economy and an all-inclusive central planning (micro-targeting) system, there is a spectrum of intermediate possibilities, some involving partial micro-targeting and some involving rules-of-the-game government intervention (with no element of planning or micro-targeting).

Personally, I tend to agree with Professor Kirzner that a large modem state is above optimal size as a micro-targeting unit. My reasons-in addition to those in the sphere of knowledge cited by Professor Kirzner-have to do with the discouragement of individual incentives ${ }^{\theta}$ toward efficiency, due to micro-targeting type planning as in the Soviet Union or China. But it does not follow that laissezfaire constitutes a universal panacea.

In particular, a proof has yet to be given that (as claimed on p. 417) "Competition between firms of different sizes and scope will tend ... to reveal the optimal extent of such "central planning." "In

9Professor Kirzncr does recognize the role of incentives in the scarch for knowlodge. I an roferring hore to incentives for efficient bohavior glven the available knowledge. 


\section{Cato Jouknal}

classical environments this might indeed be the case, but one is entitled to question whether, for instance, the present merger trends in the United States are logically bound to push the economy closer to optimality. If monopoly results, inefficiency might follow.

Let me also enter a dissent to the final statement in the paperthat the advocacy of industrial policy or central planning is necessarily ronted in the lack of awareness of the knowledge problem ("... their well-meaning advocates are totally unaware of the knowledge problem"). ${ }^{10}$ In my opinion, lack of appreciation of the importance of incentives may be a more serious problem. (China is an example of a centrally managed economy which has come to recognize the importance of incentives and the merits of decentralization.) Some advocates see industrial policy as a second-best solution in view of the imperfection of domestic and international markets and despite the difficulties due to the problem of knowledge. One may disagree with the judgment that this is indeed a second-best solution, but without imputing to its advocates lack of awareness of some of its disadvantages.

The problem of the appropriate role of markets and of government intervention is complex, and, in my view, panaceas are not to be found at either end of the spectrum. Dispassionate analysis-to which Professor Kirzner's paper is a valuable contribution-shows the merits as well as the deficiencies of polar solutions; it points to the strengths of the market process as well as those imperfections which justify the search for supplementary institutional devices involving public intervention. It is likely that the answers will not please the ideologues of either persuasion.

\section{References}

Arrow, K. J; Block, H. D.; and Hurwicz, L. "On the Stability of Competitive Equilibrium II." Econometrica 27 (January 1959): 82-109.

Calsamiglia, X. "Decentralized Resource Allocation and Increasing Returns." Joumal of Economic Theory 14 (April 1977): 263-83.

Hurwicz, L. "On the Dimensional Requirements of Informationally Decentralized Pareto-Satisfactory Processes." In Studies in Resource Allocation Processes, pp. 413-24. Edited by K. J. Arrow and L. Hurwicz. Cambridge University Press, 1977.

Kirzner, Israel M. "Economic Planning and the Knowledge Problem," Cato Joturnal 4 (Fall 1984): 407-18.

Mount, K., and Reiter, S. "The Informational Size of Message Spaces." Journal of Economic Theory 8 (June 1974): 161-92.

${ }^{10}$ Kirzner (1984, p. 417). 


\section{COMMENT ON KIRZNER}

Osana, H. "On the Informational Size of Message Spaces for Resource Allocation Processes." Journal of Economic Theory 17 (February 1978): 66-78.

Radner, Roy. "Satisficing." Joumal of Mathematical Economics 2 (1972): 253-62.

Reiter, S. "Information and Performance in the (New)' Welfare Economics." American Economic Reviewo 67 (February 1977) $226-34$.

Scarf, H. "Some Examples of Global Instability of the Competitive Equilibrium." Intermational Economic Revtew 1 (September 1960): 157-72.

Simon, Herbert $A$. "Theories of Bounded Rationality." In Decision and Organtzation, chap. 8. Edited by C. B. McGuire and R. Radner. Amsterdam: North-Holland, 1972. 